\title{
ACCURACY OF SCOTTISH HOSPITAL MORBIDITY DATA
}

\author{
E. LOCKWOOD \\ Scottish Hospital Service, Scottish Home and Health Department
}

Since 1961 the Scottish Home and Health Department has collected and processed morbidity information relating to all non-obstetric and non-psychiatric discharges from National Health Service hospitals in Scotland. The information is used for planning, administrative, and epidemiological purposes and it is therefore essential that its reliability is assessed. The present study was carried out to obtain factual information relating to the accuracy of the data collected, no previous studies having been undertaken in Scotland to evaluate the national hospital morbidity information.

Morbidity information concerning each hospital discharge is recorded on the form S.M.R.1, usually by hospital medical records staff. This basic data collection sheet, the checking and elimination of errors, and the uses to which the data are put have been fully described by Heasman (1968). These data are the basis of the Scottish Hospital In-patient Statistics published annually, the unpublished tabulations sent to all hospitals and to regional hospital boards, the individual hospital diagnostic and operation indexes, and the recently introduced Scottish Consultants Review of In-patient Statistics.

Each form received in the central department is scanned for obvious errors and omissions and is then subjected to a computer data vetting and feasibility check. These checks attempt to ensure that as many inconsistencies as possible are detected, and enable any necessary corrections to be made before final acceptance. It is, however, possible for errors to remain undetected if the information, although inaccurate, is neither infeasible nor inadmissible.

The present paper reports on the accuracy of the information received for processing in the year 1969. Errors in transcription and coding of the information recorded in the patient's medical case record are described, and an attempt is made to assess the relative importance of the levels of error found.

\section{Method}

In deriving the sample, it was necessary to restrict the survey to hospitals of one hundred or more beds in order to obtain for each individual hospital a sample sufficiently large to justify a visit. The latest available $\varrho$ figures (for 1968) suggest that these hospitals account for is $85 \%$ of the total discharges in Scotland.

From the 90 hospitals of 100 or more beds in Scotland a simple random sample of 38 hospitals was drawn and $\vec{\omega}$ permission to carry out the survey was obtained from each. The total number of forms examined represented $\widehat{D}$ $0.5 \%$ of the expected discharges in Scotland during ? 1969 , the sample size in each hospital being a uniform of sampling fraction of the total forms.

For each individual hospital a systematic sample of forms was taken, representative of all specialties within the hospital and covering a period of not less than three $\mathrm{O}$ months in the year.

The information recorded on each form S.M.R.1 was compared with that recorded in the patient's medical case record. The identifying and administrative infor- $\overrightarrow{0}$ mation relating to each patient was checked by a depare mental clerk from the Scottish Home and Health De partment; the clinical information was checked by th author.

In addition to the present report, individual reports have been issued to each hospital participating in the study. It is hoped that these may be of value in further reducing individual hospital errors.

\section{RESULTS}

A total of 2,515 forms were checked in the 38 贾 hospitals in the survey. Each form should have contained a minimum of 16 items of information for checking, and a possible maximum of 22 items. Of the 2,515 forms, $1,341(55 \cdot 3 \%)$ were considered entirely correct, $1,055(42.0 \%)$ contained one or more errors, and $119(4.7 \%)$ contained some item of information that could not be checked from the clinical record. The number of forms in error is of much less significance than the nature of the errors, $\frac{7}{0}$ and the types of error will be discussed according to whether they occurred in the identifying, adminis- $N$ trative, or clinical information.

\section{Identifying Information and Personal Data Relating to Patient}

Table I shows for each item in this section the number and percentage of entries correct, in error, omitted from the form S.M.R.1 or ambiguous. The term ambiguous is used if the item recorded on the S.M.R.1 was not recorded in the patient's 
TABLE I

IDENTIFYING INFORMATION AND PERSONAL DATA RELATING TO PATIENT

\begin{tabular}{|c|c|c|c|c|c|c|c|c|}
\hline \multirow{2}{*}{ Item } & \multicolumn{2}{|c|}{$\begin{array}{c}\text { Transcription } \\
\text { Correct }\end{array}$} & \multicolumn{2}{|c|}{$\begin{array}{l}\text { Transcription } \\
\text { Incorrect }\end{array}$} & \multicolumn{2}{|c|}{$\begin{array}{l}\text { Item Wholly or } \\
\text { Partially Omitted } \\
\text { from S.M.R.1 }\end{array}$} & \multicolumn{2}{|c|}{ Ambiguous } \\
\hline & No. & $\%$ & No. & $\%$ & No. & $\%$ & No. & $\%$ \\
\hline $\begin{array}{l}\text { Hospital code no. } \\
\text { Case reference no. } \\
\text { Surname } \\
\text { Initials } \\
\text { Date of birth } \\
\text { Sex } \\
\text { Marital status } \\
\text { Occupation } \\
\text { Area of residence }\end{array}$ & $\begin{array}{l}2,514 \\
2,508 \\
2,504 \\
2,490 \\
2,421 \\
2,499 \\
2,461 \\
2,103 \\
2,384\end{array}$ & $\begin{array}{l}99.96 \\
99.72 \\
99.56 \\
99.01 \\
96.26 \\
99.36 \\
97.85 \\
83.62 \\
94.79\end{array}$ & $\begin{array}{r}1 \\
5 \\
11 \\
23 \\
69 \\
16 \\
46 \\
112 \\
131\end{array}$ & $\begin{array}{l}0.04 \\
0.20 \\
0.44 \\
0.91 \\
2 \cdot 74 \\
0.64 \\
1.83 \\
4.45 \\
5.21\end{array}$ & $\begin{array}{r}0 \\
2 \\
0 \\
2 \\
25 \\
0 \\
8 \\
257 \\
0\end{array}$ & $\begin{array}{r}0.00 \\
0.08 \\
0.00 \\
0.08 \\
1.00 \\
0.00 \\
0.32 \\
10.22 \\
0.00\end{array}$ & $\begin{array}{r}\mathbf{0} \\
\mathbf{0} \\
\mathbf{0} \\
\mathbf{0} \\
\mathbf{0} \\
\mathbf{0} \\
\mathbf{0} \\
\mathbf{4 3} \\
\mathbf{0}\end{array}$ & $\begin{array}{l}0.00 \\
0.00 \\
0.00 \\
0.00 \\
0.00 \\
0.00 \\
0.00 \\
1.71 \\
0.00\end{array}$ \\
\hline Total & 21,884 & 96.68 & 414 & 1.83 & 294 & $1 \cdot 30$ & 43 & 0.19 \\
\hline
\end{tabular}

notes or could not be verified from other available sources. The total number for each item in this section was 2,515 , the same as the number of forms examined.

There was a total of 22,635 items capable of being recorded in the forms S.M.R.1 of which 21,884 (96.7\%) were correct, $414(1.8 \%)$ were incorrect, $294(1 \cdot 3 \%)$ were omitted, and $43(0 \cdot 2 \%)$ could not be checked. The majority of the errors and omissions were in the recording of the patient's occupation and in area of residence coding. The error level for the separate items in this section is discussed below, and the possible effects on the published and unpublished statistics are also examined.

Name, Date of Birth, and Sex. Errors in these items were few in number. The errors are important at present only in ad hoc studies requiring case listing but will assume greater importance when used for medical record linkage purposes, which will be introduced in the near future.

There were $16(0.6 \%)$ errors in recording sex, three females being coded as males and 13 males coded as females. These errors would have been detected by computer verification only if the recorded diagnosis was inadmissible for the sex. In $2,421(96.3 \%)$ forms the date of birth recorded was correct, $69(2.7 \%)$ were incorrectly transcribed, and the date of birth was omitted from the form in 25 $(1.0 \%)$. The 25 omissions of date of birth included five where it was omitted entirely and 20 where either the day or month of birth was missing.

For the purposes of relating errors in year of birth to published and unpublished statistics, the important errors are those of omission and transcription of the year of birth, data being processed into seven major age groups. The five total omissions of the year of birth would cause the form to be rejected by the computer and the hospital to be asked to state as accurately as possible the age of the patient.
There were 29 errors in transcription of the year of birth, all of which might have been acceptable providing the diagnosis was not infeasible for the age group; the remaining errors related only to the day or month. The resulting maximum number of errors in the published and unpublished statistics would then have been $29(1 \cdot 2 \%)$. These errors were randomly distributed throughout the age groups.

Marital Status. There were $54(2 \cdot 1 \%)$ errors and omissions of marital status. Of these, $46(1.8 \%)$ were coding errors and eight $(0.3 \%)$ omissions. The latter group included seven in which the marital status was unknown and one in which it was not recorded on the S.M.R.1. Although the items omitted would be rejected by the computer, the 46 errors in marital status would probably not be detected. Distributed according to marital status these 46 errors resulted in an error rate of $1.3 \%$ for single persons (12 errors in 953 persons), $1.7 \%$ for married persons (22 errors in 1,292 persons), and 4.6\% (12 errors in 252 persons) for widowed, divorced, and separated persons.

OCCUPATION. There were $257(10 \cdot 2 \%)$ forms in which no occupation was recorded and on 112 $(4.5 \%)$ forms the occupation entered was incorrect. Occupational information is required primarily in order to allocate the patient to his correct social class (General Register Office, 1966). For this purpose the appropriate occupation in the case of a married woman, a widow, or a separated woman is that of the husband. In the case of a child the appropriate occupation is that of the male parent or guardian.

The 112 errors in recording the occupation included 25 coding errors, the appropriate occupation having been correctly transcribed on to the form. Most of these coding errors were made in the central department, only three of the hospitals in the survey undertaking coding of occupation infor- 
mation abstracted on to the form. The remaining 87 errors involved the recording of an occupation, which was not the patient's current occupation, or more usually was inappropriate for social class purposes.

One difficulty encountered in the study was that a child did not seem to be adequately defined. The age of majority is now 18 years, and all persons below this age for the purposes of the study were considered to be children. The occupation required for employed persons in this group should then be that of the parent or guardian for social class purposes. A clear directive is needed for the hospitals as to which occupation should be recorded for employed persons aged 15 to 18 years.

Table II shows for each civil state the number of errors and omissions in the recording of information relating to occupation. The term ambiguous is used to denote that the information recorded on the form S.M.R.1 could not be checked, being unrecorded in the medical case record. It can be seen from the table that whereas the overall percentage of errors and omissions was $14.7 \%$, it was less than the average for males and single females, being very low for employed males. The rates for children and married women were above the average, and a very high rate was observed for widows and divorced and separated women.

As the appropriate occupation was recorded entirely correctly in $2,103(83.6 \%)$ forms, the social class would be correct in the same number, social class being derived automatically by the computer from the occupation code. In the 112 forms where the occupation was incorrect, $90(3.6 \%)$ of the errors affected the social class, the remaining 22 errors causing no social class displacement. No social class would have been allocated in the 257 omissions of the occupation, and in the remaining 43 it was not possible to check the social class assigned.

The present study shows that the recording of appropriate occupation (and hence the correct social class) was closely related to both the sex and the patient's civil state. A previous study by Car- $\infty$ stairs and Patterson (1966) showed that the omission? of social class was a function of both the age andz sex of the patient. The present study gives a similar@ result, the proportion of omissions for adults in $-\vec{z}$ creasing with age; the percentage of omissions in the age group 0-14 years was $12 \cdot 7 \%, 15-44$ years? $8 \cdot 2 \%, 45-64$ years $8 \cdot 9 \%, 65-74$ years $17 \cdot 8 \%$, and $\overline{\bar{N}}$. over 75 years $24.4 \%$.

AREA OF Residence. There were $131(5 \cdot 2 \%) \stackrel{\varrho}{0}$ errors in recording the area of residence; $12(0.5 \%)$ ( were errors in coding the city or borough, $3(0 \cdot 1 \%)$. occurred in coding residence within or without the $\vec{\omega}$ city boundary, and $116(4.6 \%)$ were errors in theo municipal ward or rural parish.

None of these errors would be detected by the computer, but only errors in the city or boroughor would be likely to affect published or unpublished? statistics. Errors in the ward or parish would affector only those ad hoc studies relating to area of resi-음 dence.

Difficulties in coding the area of residence have been fully described by Gruer (1970). The present system of coding involves the use of a census book $\vec{e}$ of place names in Scotland (General Register Offige,1967) for coding rural parishes, and the use of alo postal directory for coding municipal wards, addition to the instructions issued by the department. In the present survey the proportion of errors identified for rural parishes and municipal wards was $4.6 \%$. This was considerably less than that found by Gruer when studying a single hospital admitting patients from both a city and a surrounding rural area. That study used a much more elaborate meanso of checking the rural parishes and municipal wards including the use of one-inch ordnance survey maps? and county and valuation rolls. The error levels found by Gruer were $27 \%$ for rural parishes and. $19 \%$ for municipal wards.

The present system of recording the area of resi dence is recognized to be cumbersome and sufferso

TABLE II

ERRORS AND OMISSIONS IN OCCUPATION INFORMATION ACCORDING TO CIVIL STATE

\begin{tabular}{|c|c|c|c|c|c|c|c|c|c|}
\hline \multirow{2}{*}{ Social Status } & \multicolumn{2}{|c|}{ Correct } & \multicolumn{2}{|c|}{ Incorrect } & \multicolumn{2}{|c|}{ Omitted S.M.R.1 } & \multicolumn{2}{|c|}{ Ambiguous } & \multirow{2}{*}{$\begin{array}{l}\text { Total } \\
\text { No. in } \\
\text { Sample }\end{array}$} \\
\hline & No. & $\%$ & No. & $\%$ & No. & $\%$ & No. & $\%$ & \\
\hline $\begin{array}{l}\text { Employed male } \\
\text { Retired male } \\
\text { Child } \\
\text { Single female } \\
\text { Married female } \\
\text { Widow/divorced/separated female } \\
\text { Social status unknown }\end{array}$ & $\begin{array}{r}731 \\
180 \\
458 \\
158 \\
479 \\
97 \\
0\end{array}$ & $\begin{array}{l}96 \cdot 8 \\
85 \cdot 3 \\
79 \cdot 7 \\
90 \cdot 8 \\
76 \cdot 3 \\
57 \cdot 4 \\
\end{array}$ & $\begin{array}{r}8 \\
3 \\
41 \\
3 \\
37 \\
20 \\
0\end{array}$ & $\begin{array}{r}1 \cdot 1 \\
1 \cdot 4 \\
7 \cdot 1 \\
1 \cdot 7 \\
5 \cdot 9 \\
11 \cdot 8 \\
-\end{array}$ & $\begin{array}{r}15 \\
25 \\
67 \\
13 \\
88 \\
47 \\
2\end{array}$ & $\begin{array}{r}2 \cdot 0 \\
11 \cdot 8 \\
11 \cdot 6 \\
7 \cdot 5 \\
14 \cdot 0 \\
27 \cdot 8 \\
-\end{array}$ & $\begin{array}{r}1 \\
3 \\
9 \\
0 \\
24 \\
5 \\
1\end{array}$ & $\begin{array}{l}0.1 \\
1.4 \\
1.6 \\
0.0 \\
3.8 \\
3.0 \\
\end{array}$ & $\begin{array}{r}755 \\
211 \\
575 \\
174 \\
628 \\
169 \\
3\end{array}$ \\
\hline$\overline{\text { Total }}$ & 2,103 & 83.6 & 112 & $4 \cdot 5$ & 257 & $10 \cdot 2$ & 43 & $1 \cdot 7$ & 2,515 \\
\hline
\end{tabular}


TABLE III

ADMINISTRATIVE INFORMATION

\begin{tabular}{|c|c|c|c|c|c|c|c|c|c|}
\hline \multirow{2}{*}{ Item } & \multirow{2}{*}{$\begin{array}{c}\text { No. } \\
\text { of } \\
\text { Items }\end{array}$} & \multicolumn{2}{|c|}{ Correct } & \multicolumn{2}{|c|}{ Incorrect } & \multicolumn{2}{|c|}{ Omitted S.M.R.1 } & \multicolumn{2}{|c|}{ Ambiguous } \\
\hline & & No. & $\%$ & No. & $\%$ & No. & $\%$ & No. & $\%$ \\
\hline $\begin{array}{l}\text { Date on waiting list } \\
\text { Date of admission } \\
\text { Source of admission } \\
\text { Date of discharge } \\
\text { Discharge code } \\
\text { Specialty on discharge } \\
\text { Consultant on discharge } \\
\text { Date of operation }\end{array}$ & $\begin{array}{l}1,074 \\
2,515 \\
2,515 \\
2,515 \\
2,515 \\
2,515 \\
2,515 \\
1,295\end{array}$ & $\begin{array}{r}915 \\
2,473 \\
2,439 \\
2,425 \\
2,500 \\
2,482 \\
2,285 \\
1,198\end{array}$ & $\begin{array}{l}\mathbf{8 5} \cdot 20 \\
98 \cdot 33 \\
96 \cdot 98 \\
96 \cdot 42 \\
99 \cdot 40 \\
98 \cdot 69 \\
90 \cdot 85 \\
92 \cdot 51\end{array}$ & $\begin{array}{r}20 \\
41 \\
76 \\
90 \\
15 \\
33 \\
161 \\
36\end{array}$ & $\begin{array}{l}1.86 \\
1.63 \\
3.02 \\
3 \cdot 58 \\
0.60 \\
1.31 \\
6.40 \\
2.78\end{array}$ & $\begin{array}{r}\mathbf{2 0} \\
\mathbf{0} \\
\mathbf{0} \\
\mathbf{0} \\
\mathbf{0} \\
\mathbf{0} \\
\mathbf{0} \\
\mathbf{6 1}\end{array}$ & $\begin{array}{l}1 \cdot 86 \\
0.00 \\
0.00 \\
0.00 \\
0.00 \\
0.00 \\
0.00 \\
4 \cdot 71\end{array}$ & $\begin{array}{r}119 \\
1 \\
0 \\
0 \\
0 \\
0 \\
69 \\
0\end{array}$ & $\begin{array}{r}11 \cdot 08 \\
0.04 \\
0.00 \\
0.00 \\
0.00 \\
0.00 \\
2.74 \\
0.00\end{array}$ \\
\hline Total & 17,459 & 16,717 & $95 \cdot 75$ & 472 & $2 \cdot 70$ & 81 & 0.46 & 189 & 1.08 \\
\hline
\end{tabular}

from several defects, but there is at present no acceptable alternative. It is likely that the new General Post Office postal code system will provide an effective substitute when it has been applied to the whole country.

\section{ADMINISTRATIVE INFORMATION}

Table III shows the items of information included under this heading and indicates the number and percentage of errors for each item. In this section, the total number of items capable of being recorded on the forms was 17,459 , of which $16,717(95 \cdot 8 \%)$ were correct, $472(2.7 \%)$ were incorrect, $81(0.5 \%)$ were omitted, and $189(1 \cdot 1 \%)$ could not be checked.

Date on Waiting List. There were 1,074 patients admitted from the waiting list, and in 20 of these the waiting list date recorded on the form S.M.R.1 was incorrectly transcribed. There were $\mathbf{2 0}$ omissions of the waiting list date, usually occurring in conjunction with a mistake in the source of admission. In this section $119(11.1 \%)$ of the waiting list dates stated on the form could not be checked, the commonest reason for this being that a separate waiting list was kept and was destroyed once the patient had been admitted to hospital. Computer verification would be unlikely to pick out these errors, and the omissions would be found only if the source of admission stated was infeasible for the particular diagnosis of the patient.

Twelve of the 20 errors were of less than one week and all tended to be self-cancelling, so that it is unlikely that published and unpublished tabulations relating to the length of time on the waiting list would be in any way affected.

Date of Admission and Date of Discharge. There were $41(1.6 \%)$ errors in the date of admission and $90(3.6 \%)$ in the date of discharge. However, 38 of the errors in the date of admission and 87 errors in the date of discharge were less than one week out.
As with the other items so far discussed, these would be subject to computer verification, but many of the errors, being less than one week wrong, would probably escape detection unless other dates, for example that of operation, made either unacceptable. The errors tended to be self-cancelling, and it is unlikely that national tables dealing with the mean duration of stay derived from these items would be affected to any appreciable extent.

SOURCE OF Admission. There were 76 (3.0\%) errors in the source of admission. Distributed according to the nine sources of admission the percentage error in each was as follows:

Emergency-road traffic $\quad 0 \%$ (49 forms) accident

Emergency-home $\quad 0 \%$ (22 forms) accident

Emergency-self-inflicted injury or poisoning

Emergency-other poisoning

Emergency-not injury or poisoning

Admission from waiting list or booked case

Transfer within the same hospital

Transfer of baby from maternity nursery

Transfer from other hospitals
$6.5 \%$ ( 2 errors in 31 forms)

$11 \cdot 1 \%$ ( 1 error in 9 forms)

$2.4 \%$ (24 errors in 1,000 forms)

$3.7 \%$ (41 errors in 1,118 forms)

$2.9 \%$ ( 1 error in 34 forms)

$12.5 \%$ ( 2 errors in 16 forms)

$5 \%$ ( 5 errors in 101 forms)
Most of the errors would be undetected by computer verification as only a small proportion would have a source of admission infeasible with the diagnosis.

Specialty on Discharge. There were $33(1 \cdot 3 \%)$ errors in the recording of the specialty on discharge. The specialty is important, as several of the published and unpublished tables list diagnosis information by 
specialty. The errors were in general distributed randomly throughout the 34 specialties with the exception of dental surgery which had 21 forms in the sample, five of which were incorrectly ascribed. This was generally due to the fact that many consultant dental surgeons do not have designated beds, the specialty recorded being that normally using the beds in which the patients were treated.

Consultant on Discharge. Of the consultant codes recorded $161(6.4 \%)$ were incorrect according to the rules laid down by the Scottish Home and Health Department (1967). The Department has asked that the code number of the consultant in charge of the case be recorded. This allows each consultant to receive information relating to his own patients in the Scottish Consultant Review of In-patients Statistics but does not preclude amalgamation of these data into unit or divisional results. Several units were found to use the code number of only one of the consultants, which means that data could never be supplied to an individual consultant should he desire this for any particular purpose.

In $69(2.7 \%)$ forms the consultant code recorded could not be checked as there was no mention in the clinical notes of the consultant in charge of the case.

The errors in the consultant code would not be detected by the computer unless the consultant code recorded was unallocated. The errors in recording the consultant code in no way affect published and unpublished tables but affect the hospital disease indexes and individual consultant data.

Date of First Operation. There were 36 (2.8\%) errors and $61(4.7 \%)$ omissions in the date of operation; the latter occurred in association with the omission of the operation and so would be undetected. The majority of the errors were small, 23 of the 36 errors being errors of only one day, and they would be unlikely to be detected by computer verification unless other dates, for example the date of admission or discharge, made them infeasible.

\section{DiAgNOSIS AND OPERATION INFORMATION}

The form S.M.R.1 allows for up to three diagnoses and two operations for each discharge, the principal diagnosis and operation being entered in the first position, and it is from this that the statistical tables are produced.

Diagnoses are coded using the four-digit I.C.D. number (W.H.O., 1967), and operations are coded using a three-digit G.R.O. number (General Register Office, 1956). For published and most unpublished tables these are amalgamated into a short
TABLE IV

ERRORS AND OMISSIONS IN PRINCIPAL DIAGNOSIS :

\begin{tabular}{|c|c|c|}
\hline & No. & 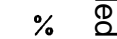 \\
\hline $\begin{array}{l}\text { Principal diagnosis correct } \\
\text { Principal diagnosis incorrect } \\
\text { Coding error } \\
\text { Misplacement } \\
\text { Omission }\end{array}$ & $\begin{array}{r}2,358 \\
44 \\
38 \\
75\end{array}$ & 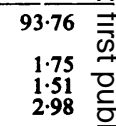 \\
\hline Total & 2,515 & $100.00 \overline{\bar{C}}$ \\
\hline
\end{tabular}

list of 100 diagnostic groups and 88 operation groups. The hospital diagnostic indexes and ad hoc requests are, however, produced by I.C.D. number and operation indexes by G.R.O. number. It is therefore, necessary to examine the effect of erro both by short list, I.C.D., and G.R.O. groupings.

Principal Diagnosis. Table IV lists the numbert of errors and omissions in the principal diagnosis. In $2,358(93.8 \%)$ the principal diagnosis was cons sidered to have been transcribed and coded correctly? There were $44(1.8 \%)$ forms in which transcriptio was correct but the principal diagnosis had been wrongly coded. In $38(1.5 \%)$ the principal diagnosis. had not been entered in the first position and bag been relegated either to the second or third positinn. In 74 forms $(2.9 \%)$ the principal diagnosis entirely omitted, and in one no diagnosis was entemed on the form. There was no form in which both $\overline{\bar{\theta}}$ misplacement and a coding error occurred togetheơ

Omitting the one form in which no diagnosis was recorded (this record would have been rejected bF the computer), there were 156 forms in which the diagnosis code entered in the first position was incorrect. These incorrect entries would have affected published and unpublished tables produced by the short list category on 148 occasions $(5.9 \%)$ In the remaining eight, although the diagnosis codo recorded in the first position was incorrect, it be longed to the same short list category as the true diagnosis. The errors in allocation of the principal diagnosis to the correct category were randomls distributed throughout each category, and showed no marked association with any particular specialty age group, or sex.

Hospital disease indexes, the national disease index, and occasional ad hoc requests are all prof duced by fourth digit I.C.D. code; the error anfe omission level in these data would then be $6.2 \%$ (156 errors and omissions in 2,515 forms).

Second and Third Position Diagnoses. I I 616 of the total forms it was considered that a second diagnosis should have been entered. these, $408(66.2 \%)$ were correctly transcribed an 
TABLE V

ERRORS AND OMISSIONS IN SECOND AND THIRD POSITION DIAGNOSES

\begin{tabular}{|c|c|c|c|c|}
\hline & \multicolumn{2}{|c|}{$\begin{array}{l}\text { Second } \\
\text { Diagnosis }\end{array}$} & \multicolumn{2}{|c|}{ i. Diagnosis } \\
\hline & No. & $\%$ & No. & $\%$ \\
\hline $\begin{array}{l}\text { Diagnosis correct } \\
\text { Diagnosis incorrect } \\
\text { Coding error } \\
\text { Misplacement (to position 1) } \\
\text { Onission } \\
\text { Inappropriate entry }\end{array}$ & $\begin{array}{r}408 \\
1 \\
35 \\
164 \\
8\end{array}$ & $\begin{array}{r}66 \cdot 23 \\
0 \cdot 16 \\
5 \cdot 68 \\
26 \cdot 62 \\
1 \cdot 31\end{array}$ & $\begin{array}{r}90 \\
1 \\
3 \\
48 \\
5\end{array}$ & $\begin{array}{r}61 \cdot 22 \\
0 \cdot 68 \\
2 \cdot 04 \\
32 \cdot 66 \\
3 \cdot 40\end{array}$ \\
\hline Total & 616 & 100.00 & 147 & 100.00 \\
\hline
\end{tabular}

coded, $208(33.9 \%)$ being incorrect. Table V shows the numbers and types of error in the second diagnosis. The eight forms containing an inappropriate diagnosis were forms in which, although a second diagnosis was required, the recorded diagnosis was not that which should have been recorded. In addition to these errors, and not shown in the table, there were six entries in the second position which were considered to be superfluous entries. These superfluous entries, together with the eight inappropriate entries, almost invariably represented the provisional admission diagnosis, being recorded in addition to the true discharge diagnosis.

Table $\mathrm{V}$ also shows the number of errors in the third position diagnosis. It was considered that three diagnoses should have been recorded on 147 forms. These were correctly transcribed and coded in $90(61.2 \%)$ and were incorrect in $57(38.8 \%)$.

Most of the errors, $48(32 \cdot 7 \%)$, were again due to the omission of the third diagnosis. There were no additional entries in the third position. As published, unpublished, and individual consultant tables are based on the principal diagnosis only, they would not have been affected by errors in this section. Second and third diagnoses are recorded for the purpose of producing diagnostic indexes and to allow ad hoc study of, for instance, associated conditions. There were 156 errors and omissions in the first diagnosis, 208 in the second diagnosis, and 57 in the third diagnosis. The total number of diagnoses which should have been recorded was 3,378 . The maximum level of errors and omissions in the diagnostic indexes would then be $12 \cdot 1 \%$.

It has beeh suggested to the central department that for ad hoc study purposes allowance for more than three diagnoses is necessary. In the present study, however, only 21 of the 2,515 medical records examined listed more than three diagnoses.

Principal Operation. There were 1,294 forms in which it was considered that at least one operation should have been entered. The principal operation
TABLE VI

ERRORS AND OMISSIONS IN OPERATION INFORMATION

\begin{tabular}{|c|c|c|c|c|}
\hline & \multicolumn{2}{|c|}{$\begin{array}{l}\text { Principal } \\
\text { Operation }\end{array}$} & \multicolumn{2}{|c|}{$\begin{array}{l}\text { Second Position } \\
\text { Operation }\end{array}$} \\
\hline & No. & $\%$ & No. & $\%$ \\
\hline \multirow{2}{*}{$\begin{array}{l}\text { Operation correct } \\
\text { Operation incorrect } \\
\text { Coding error } \\
\text { Misplacement } \\
\text { Omission } \\
\text { Inappropriate entry }\end{array}$} & 1,161 & 89.72 & 196 & $75 \cdot 10$ \\
\hline & $\begin{array}{l}13 \\
36 \\
74 \\
10\end{array}$ & $\begin{array}{l}1.01 \\
2.78 \\
5.72 \\
0.77\end{array}$ & $\begin{array}{r}2 \\
36 \\
27 \\
0\end{array}$ & $\begin{array}{r}0.77 \\
13.79 \\
10.34 \\
0.00\end{array}$ \\
\hline Total & 1,294 & $100 \cdot 00$ & 261 & $100 \cdot 00$ \\
\hline
\end{tabular}

was correctly transcribed and coded on 1,161 $(89.7 \%)$. There were $13(1.0 \%)$ forms in which the principal operation had been incorrectly coded, and in $36(2.8 \%)$ it was relegated to the second position. The most frequent fault, which occurred $74(5.7 \%)$ times, was omission of the principal operation. There were 10 forms containing an inappropriate entry; in these, although an operation was required, the recorded operation was not that which should have been entered. These results are summarized in Table VI. In addition to the errors shown in the table there was one instance of a superfluous entry on the form, the operation quoted referring to an earlier admission to hospital.

The 74 omissions of the principal operation would remain undetected by the computer and so be lost to published and unpublished statistics. Examination of the omissions by specialty shows that the percentage of omissions of the principal operation varied within the specialties. For general surgery it was $2.4 \%$ ( 15 omissions in 630 operations). In urology the omission rate was $11 \cdot 1 \%$ (8 omissions in 72 operations), in orthopaedic surgery $6.9 \%$ (15 omissions in 218 operations), and in dermatology $10.7 \%$ ( 3 omissions in 28 operations). Most of the omissions for urology were due to the omission of cystoscopies when the patient had been admitted for this procedure only. The most frequent omission in orthopaedic surgery was manipulation of a fracture, and in dermatology it was skin biopsy.

The 59 errors due to coding, misplacement, and recording of an inappropriate operation would have affected the published and unpublished tables on 45 occasions. In 14 there was no displacement of the true principal operation from its correct short list group, although the operation code recorded as the principal was incorrect. The errors were randomly distributed throughout the various short list groups and showed no association with any particular specialty, age group, or sex. The overall error and omission level for the principal

$$
\frac{2}{2}
$$


operation produced by short list group was $9 \cdot 2 \%$ (45 errors plus 74 omissions).

For the operation indexes and ad hoc requests produced by G.R.O. number the overall level of errors and omissions was $10.3 \%$ (59 errors plus 74 omissions).

SECOND Position Operation. In 261 of the total forms it was considered that a second operation should have been entered. Of these, $196(75 \cdot 1 \%)$ were correctly transcribed and coded and $65(24.9 \%)$ were incorrect. Table VI shows the numbers and types of error in the second operation, the majority being either omissions or misplacements. There were no inappropriate operations entered in the second position and no additional entries.

As the published and unpublished tables are based only on the principal operation, they would not have been affected by errors in this section. The second position operation is recorded in the operation indexes and these would be affected by the errors. It has been shown that there were 133 errors and omissions in the principal operation and 65 in the second operation. The total number of operations that should have been recorded was 1,555 . The overall level of errors and omissions in the operation indexes was found to be $12 \cdot 7 \%$. Of the 2,515 medical records examined, there were only 13 in which more than two operations were recorded.

\section{Discussion}

The study has attempted to assess the likely maximum level of errors and omissions in hospital morbidity data due to errors in transcription and coding of information contained in patients' medical case records. It has, therefore, described only one of the possible sources of error, no attempt being made to check that the information in the case records was itself entirely correct. In some instances where the information relating to the diagnoses and operations was not clearly recorded it was necessary for the author to allocate a diagnosis or symptom complex using such information as was available. This in general did not present any great difficulty, but the same may not necessarily be true for the medical records staff, who at the best have only limited medical knowledge. It was because of this that the Committee on Hospital Medical Records in Scotland (Scottish Home and Health Department, 1967) recommended that the consultant in administrative charge should be responsible for ensuring the accuracy and completeness of the Hospital Inpatient Record Summary Sheet (form S.M.R.1).

The error and omission level in identification and administrative information due to transcription faults has been shown to be small with the exception of information relating to social class. National data relating to the principal diagnosis have been show to be correctly transcribed from $94 \%$ of the record? examined, and data relating to the principal operatio were approximately $90 \%$ accurate. Information about subsidiary diagnoses and operations was found to be much less accurate due largely to omissions in the information, and there is little doubt that this was due mainly to medical record? clerks being unable to pick out the salient facts if⿱艹 those records which were poorly structured. Wherg the information necessary was available to the medical records clerk it was transcribed and coded well, most of the errors and omissions in the clinicas data being due to the clerk not knowing whas information she should be recording.

\section{SUMmaRY}

A study into the accuracy of transcription of hospital morbidity data was undertaken in 38. hospitals throughout Scotland. Information con tained in 2,515 morbidity returns was compared wit the information recorded in the hospital medical case records. Errors and omissions in the transcripe tion and coding of the hospital case refereace number and the patient's name and sex, were eacte less than $1 \%$, but errors and omissions in the tat of birth were $3.7 \%$, and in occupation $14.7 \%$ Items of administrative importance relating to duration of stay and time spent on the waiting lisis were shown to contain errors of only minor signifi cance despite errors and omission levels of up t $\bar{乛}$ $3 \%$ for individual items. Data relating to the principal diagnosis were correctly transcribed an $\overrightarrow{\text {. }}$ coded in $94 \%$ of the forms examined, and infor mation relating to the principal operation was correct in $90 \%$. The greatest error and omissio levels were found for information relating to sub? sidiary diagnoses, which were shown to be recorde $\$$ accurately in only two-thirds of relevant cases, and a second operation was transcribed correctlo for only $75 \%$ of relevant cases.

I should like to thank the medical records staff if each hospital for their co-operation and help, and Df J. Donnelly who was responsible for much of the hard work in designing this study. I am grateful to Dr. M. AD Heasman for constructive criticism in preparing and formulating this paper, and to the medical staff in each hospital for permission to examine the medical case records.

\section{REFERENCES}

Carstairs, V., and Patterson, P. E. (1966). Distributio of hospital patients by social class. Hlth Bull. (Edinb. 暮 24, no. 3 , p. 59. 
General Register Office (1956). Code of Surgical Operations. H.M.S.O., London.

(1966). Classifications of Occupations. H.M.S.O., London.

(1967). Place Names and Population, Scotland. H.M.S.O., Edinburgh.

GRUER, R. (1970). Hospital discharges in relation to area of residence. Brit. J. prev. soc. Med., 24, 124.
Heasman, M. A. (1968). Scottish Hospital In-patient Statistics-sources and uses. Hlth Bull. (Edinb.), 26, no. 4, p. 10.

Scottish Home and Health Department (1967). Hospital Medical Records in Scotland. H.M.S.O., Edinburgh.

World Health Organization (1967). Manual of the International Statistical Classification of Diseases, Injuries, and Causes of Death. Based on the Recommendations of the Eighth Revision Conference, 1965. W.H.O., Geneva. 